\title{
Critical Future Studies and Age: attending to future imaginings of age and ageing
}

\author{
By \\ Jayne Raisborough \& Susan Watkins
}

\begin{abstract}
This paper draws on cultural gerontology and literary scholarship to call for greater academic consideration of age and ageing in our imaginations of the future. Our work adds to the development of Critical Future Studies (CFS) previously published in this journal, by arguing that prevailing ageism is fuelled by specific constructions of older populations as a future demographic threat and of ageing as a future undesirable state requiring management and control. This paper has two parts: the first considers the importance of the future to contemporary ageist stereotypes. The second seeks potential counter representations in speculative fiction. We argue that an age-aware CFS can allow us not only to imagine new futures but also to reflect critically on the shape and consequences of contemporary modes of relations of power.
\end{abstract}

Keywords: Ageism, Critical Future Studies, Cultural Gerontology, Ninni Holmqvist, Speculative Fiction, John Wyndham

Raisborough, Jayne \& Watkins, Susan: "Critical Future Studies and Age: attending to future imaginings of age and ageing", Culture Unbound, Volume 13, issue 2, 2021: 15-37. Published by Linköping University Electronic Press: http://www.cultureunbound.ep.liu.se 


\section{Culture Unbound}

\section{Introduction}

This paper calls for greater academic consideration of age and ageing in imagining the future. We might speak of a "revival" of the future in social science and cultural studies scholarship (Schultz 2015, Coleman 2017) and this new focus has been usefully articulated in this journal in proposals for a new "critical future studies" (CFS) (Goode, and Godhe 2017, Godhe and Goode 2018). The starting point for CFS is that wide, diverse and readily contestable imaginations of the future are vital for its democratization. There is an underpinning sociological concern that futures may be shaped and foreclosed by prevailing power relations to the detriment of already-marginalized and newly stigmatized groups. To keep the workings of power central, CFS focuses on the key question of who futures are for. This entails an examination of how societies imagine futures in their science, journalism, literature and popular culture to see how futures are being variously shaped. CFS also insists on the creation of broader and more diverse alternative "futural frames of reference and possibility" (Godhe and Goode 2018: 153). These deconstructive and reconstructive impulses form the "ethical commitment" of CFS, which is to stimulate and widen public engagement with the "widest possible repertoire of imagined futures", regarded as a pre-requisite for any democratization of the future.

This paper argues that there is a need for closer work on cultural representations of ageing, which CFS can encourage and enable. Our starting point is that ageing enters the contemporary socio-cultural imagination in terms of its futurity. On one hand, demographic sciences predict, expect, or forecast the ageing of populations. On the other hand, ageing is represented as a future state of failure that must be managed and deferred. Taken together, these tendencies can steadily produce ageing as a stigmatized identity and ultimately as a culturally feared state (Parcei 2019), and as a site for discrimination and prejudice (Calasanti 2020). This has dire consequences for present and future democratization. Yet, in a meta-analysis of English language ageing research between 2000-2015 (Iversen and Wilinska 2019), there is no specific mention of how age and ageing are considered in our imagination of the future.

This paper brings cultural gerontology (CG) into dialogue with CFS by addressing the key question Michael Godhe and Luke Goode (2018) pose in their introduction to CFS. Our aim is to demonstrate how imaginations of the future are deployed in contemporary representations of age and ageing. This route is consistent with a CFS interest in how present assemblages of power aim to establish a favoured future, and in how these imaginations feed back into present structures and relations of power. In the second part of the paper we bring CG and CFS together to question how science fiction (SF) and speculative fiction $(\mathrm{SpF})$ in particular might both sustain and challenge futural narratives about age 


\section{Culture Unbound}

and ageing. SF has often imagined ageing in terms of a "technoscientific fantasy of indefinitely extending longevity" (LaFontaine 2009: 530) and of perpetually enhanced bodies (Delgado et al 2012), with promises of biomedical technical breakthroughs to bio-engineer ageing out (Slusser et al 1996). However, this paper attends to Katherine Woodward's claim that speculative fiction "[has] the goal of returning to our own [world] enlivened with deeper understanding and insight, renewed energy, and fresh perspectives on how to build our age world in meaningful and just ways" (2019: 376). Woodward's suggestion that literary texts have an important role in allowing us to imagine age differently is key to our argument. We conclude by promoting a discussion about what a critical inclusion of age and ageing might mean for the remit and focus of CFS.

\section{Age and Ageing: Taking a Cultural Approach}

Our approach is influenced by the diverse work that forms Cultural Gerontology (CG). CG is a critical response to predominantly biomedical models that regard ageing as an essentialized, pre-discursive state of decline (Twigg and Martin 2015). Instead, CG understands age and ageing to occur in cultural and societal contexts that mediate how ageing is experienced and understood: in short, age and ageing is understood as a social construct (Gullette 2004) that is reproduced and circulated, in part, though cultural representations (Ylänne 2012). CG does not ignore the material realities of ageing; rather, it re-reads ageing as diverse cultural events that reach across our life course. Margaret Morganroth Gullette (2011: 5), for example, approaches decline as "an entire system that worsens the experiences of ageing-past-youth". She encourages us to regard ageing as a narrative, recognizing that cultural stereotypes of older people as worthless, demented and burdensome weigh heavily on our ageing autobiographies. Further, she identifies a "decline ideology" that justifies various acts of discrimination against older people, such as restrictions in employment, pay, housing and medical care.

CG scholarship is also alert to an observable shift in cultural representations of older people that started in the 1980s in the US and UK (Boudiny 2012). The shift was towards cultural representations of age and ageing as matters of lifestyle and consumer choices related to leisure, travel, romance and the maintenance of good physical health and mobility (Givshov and Petersen, 2018). This framing is problematic, not least because it denies the material realities of age and ageing and assumes middle-class, white, heteronormative privilege as a universal norm (Marshall 2018). In short, CG offers space to criticize the progressive medicalization of age and the "good ageing" narratives. It aims to foreground polysemic discourses and meanings of ageing, their socio-cultural contexts 


\section{Culture Unbound}

Journal of Current Cultural Research

(Pickard 2014), and the heterogeneity of ageing populations in order to create new narratives and new possibilities for being (Edström 2018).

This is a brief introduction to CG but it is possible to discern some common ground with CFS. Both share a deconstructive/ reconstructive ethic: they hitch the work of the contestation of prevailing cultural narratives to the generation of alternative imaginings, which both see as necessary to social equality and justice. We now move to bring CG and CFS into closer dialogue by addressing the key questions posed by Michael Godhe and Luke Goode (2018:153).

\section{Critical Future Studies and Ageing}

\section{Who can speculate with authority and legitimacy about the future?}

Futural representations of age and ageing are dominated by demographic science. Demographic predictions suggest that many countries worldwide are facing unprecedented population ageing (Macia et al, 2019). These predictions have been endorsed by World Health Organisation (WHO) United Nations (UN) and European Commission (EC) (Carney, 2018). The UN, for example, states that

In 2018, for the first time in history, persons aged 65 or above 80 years or over is projected to triple, from 143 million in 2019 to 426 million in 2050. (UN World Population Prospects: the 2019 Revision)

Despite the certainty presented here, demographers themselves acknowledge degrees of uncertainty in their predictions (Teitelbaum 2015, Coleman et al, 2015): not least because the three main contributory factors to population changes fertility, migration and mortality - can be dramatically altered by social policies (family-friendly policies, migration policies) or by climate change or new diseases (Gee, 2002). For example, life expectancy rates have been negatively impacted by austerity policies in the UK over the last 10 years (Marmot, 2020). Demographers are clear, then, that "demography is not destiny" (Harper 2018).

Yet, large-scale population changes make for good news headlines and are readily taken up by the media and politicians in ways that create a demographic determinism about the future (Smallwood 2019, Coleman et al 2015). Significantly, demographic "facts" fuel alarmist predictions of the financial costs and social implications of an older, dependent population. Metaphors such as "grey tsunami", "demographic ticking timebomb" help to represent future older people as a "definite, but vaguely characterised threat" (Lundgren \& Ljuslinder 


\section{Culture Unbound}

Journal of Current Cultural Research

2011: 41) There may be nothing new here, Susan Pickard (2019: 370) argues that the media have a long history of scapegoating "the old" in times of financial uncertainty. What is new is an aggressive circulation of what she argues is a "intergenerational warfare discourse" in UK media. (2019: 382). This positions future and contemporary older populations as stealing the financial future of the young, through their "costly" pensions and expected "excessive" use of health-care services. A similar construction was evident in news media reporting of the UK's 2016 referendum on membership of the European Union when older people were reported as denying younger people their "future" through their "leave" vote (Liberini et al 2017). From this brief account, we can argue that authoritative and authorised versions of the future deploy the future in two ways: to misrepresent older people as a future demographic threat upon imagined scarce resources and as a current political threat to the future of others.

\section{Whose imagined futures are deemed possible and plausible?}

Godhe and Goode's (2018: 153) second question forces us to look closely at just who imagined futures are for. This question takes us to examine the favoured response to future demographic changes: active ageing. Endorsed by the World Health Organisation, active ageing refers to a suite of policies and initiatives aimed at reducing the impact, and cost of predicted older populations, by encouraging and supporting people's health, independence and social inclusion for as long as possible (Boudiny, 2013). What emerges across active ageing are "descriptive categories", "positive visions" and "prescriptive claims" that together craft a pervasive imaginary of future older citizens and the "good life" they are expected to enjoy (Pfaller and Schwed, 2019:44). CG scholars have long observed how these imaginaries extend current social privileges: Barbara Marshall's (2018) analysis of health promotion materials and lifestyle magazines aimed at middle-aged people concludes that what she calls "anticipatory ageing" (p.363) equates a successful older life with the ability to continue one's socio-cultural privileges through into later life. Her work demonstrates how heteronormativity, racialized and class privilege and their attendant material advantages shape who is imagined to be old. Relatedly, other work offers more detail on how the "good life" is attuned to specifically middle-class tastes and finances: the consumption of leisure activities, travel, romance and the biomedical aides to help control health and manage the process of ageing itself (Ylänne, 2012). What is striking about these imaginaries is the absence of the physical bodily changes that come with age (Westwood, 2019) and an overall endorsement for "growing older without aging" (Katz, 2005, 188). The significance of this is drawn out below, but it is worth reiterating that authorised imaginations project hegemonic privileges into the future. 


\section{Culture Unbound}

\section{Whose imagined futures are silenced or dismissed as unrealistic or impractical?}

This third question forces attention to the consequences of the ideal "active ager" described above. An immediate concern is with those who are effectively erased from the future: as Barbara Marshall (2018) warns of the "heterohappy" that marks successful ageing, Jane Traies (2016) observes the omission of older lesbians from popular culture. Further, as successful ageing is narrowly defined to activity and consumption, other ways of ageing are devalued or omitted. Rob Ranzljn's (2010) study of Aborigine elders found that culturally diverse approaches to ageing, including a valuing of passivity, not only fell outside the tightly-defined notions of "active ageing" but increased the marginalisation and stigmatisation of those communities. This last point speaks to the moralisation of ageing that circulates through active ageing (Coupland, 2009); if "good" ageing is signalled through the exercise of personal will-power, consumption, and responsibility, then "doing" ageing differently - indeed showing one's age - can be read as a personal failure (Raisborough, et al, 2014). This has increased significance when the ones deemed to have personally failed are those who are already disadvantaged and marginalised by stratifying power relations: they come to embody the old person so feared in apocalyptic demography, with significant consequences for the way older people are perceived and treated (Nelson, 2005). There is a further consequence of our ageing: we are encouraged to fear or deny a "body that is anything but optimal" and thus our future selves (Ellison, 2020:39).

\section{Who benefits from promoting particular visions of the future?}

The question "who benefits" forces attention to the consequences of apocalyptic demography. These are not confined to the future: they have present effects. Alarmist predictions of the "skyrocketing costs" of health care required by older populations (Evans et al 2001: 160) have been mobilized by politicians in North America, Sweden and the UK, inter alia, as justification for contemporary health restructuring and welfare reform. Lynne Segal (2013) observes how neoliberal notions of self-responsibility become a key "cure" for the problems of an ageing population just at the time of this "restructuring". For her, "active ageing" policies and construction of the future old-but-not aging citizen are part of a wider "anti-welfare agenda" (Segal 2013 18). A central element to the erosion of welfare is the abstraction of the structural determinants of health and the increasing stigmatisation of those who are structurally disbarred from "success" (Westwood, 2019). Political agendas may well benefit from visions of the future, but so do the industries developing "treatments" for ageing, which are predicted to grow from US $\$ 140.3$ billion in 2015 to US $\$ 216.52$ billion by 2021 (Petersen 2018), Kirsten 


\section{Culture Unbound}

Journal of Current Cultural Research

Ellison (2020) argues that their influence is reshaping our understanding of what it is to be human, handing our lives over to the marketized metrics.

\section{Where do these ideas and visions of the future come from?}

We might look to the association of ageing with death as a reason for futural representations of prolonged and non-aging lives. Yet stigmatization of older people may be more recent and closely tied to social change. Todd Nelson's brief history of ageism in the US looks to two developments that have unintentionally marginalised older people. The first is the printing press that eroded elders' position as "custodians of traditions and history" (2005 208) in their groups and the second is the industrial revolution that forced families apart, producing the older person as someone to be specially managed, often from afar, and found older people lacking in a new emphasis on mobility and adaptability. Both of these speak to the presumed inability of older people to be "productive" at times when productivity becomes a measure of worth.

There are also wider changes in health that pertain to idealistic visions of the future and to the stigmatisation of bodies who age. Healthism was coined by Robert Crawford (1980) to address a redefinition of health, from something one has to something one does. He argued that health had become a site for the exercise and presentation of one's responsibility. CG scholars claim that as material bodies and structural determinants of health are neatly abstracted in the face of personal agency, ageing emerges as something that can, and should, be managed and ideally reversed as a performance of viable, responsiblised personhood (Coupland 2009). Popular culture teaches us to shame the aging bodies of others, whilst staying alert to our own signs of ageing (Raisborough et al 2014). We suggest that current futural representations of ageing emerge from an orchestration of varied interests: neoliberal organisation, its specific impact on health, cultural fears of death and decline, and a successful anti-ageing industry which turns ageing anxieties into commercial success.

\section{Science Fiction and Story-telling}

The experience of reading fiction necessitates an engagement with an imagined future via the process of projection (imagining what might happen to characters in a novel, or speculating about the outcomes of a book's plot). This process is central to and can be manipulated by specific use of narrative techniques, for example what Gerard Genette (1980: 40) refers to as prolepsis, or "any narrative manoeuvre that consists of narrating or evoking in advance an event that will take place later". More specifically, Science fiction (SF) and Speculative fiction (SpF) work 


\section{Culture Unbound}

to engage readers' investment and critical engagement in the future by the device of extrapolation. As David Samuelson (2009) argues "the 'what if?"' on which SF is based, depends on "speculation [...] commonly by means of extrapolation and transformation." Additionally, across all genres the choice of narrative points of view also necessitates a concomitant choice about perspective on imagined futures: whose future is allowed scope by being permitted a viewpoint and whose is not? The ethical investment generated by writing and reading from the perspective of those who exist at a tangent to, or are othered by, the majority is often used to justify the importance of literature. See for example Derek Attridge's (2004: 131) claim that "it is in this apprehension of otherness and in the demands it makes that the peculiar pleasure of the literary response $[\ldots]$ is to be experienced."

Visions of the future in SpF texts are often divided into the utopian and the dystopian, yet Margaret Atwood (2011: 66) has created the term ustopia: "a word I made up by combining utopia and dystopia - the imagined perfect society and its opposite - because, in my view, each contains a latent version of the other." This may offer different representational possibilities; however, in the main, imagined futures in relation to ageing are often dystopian, frequently hinging on apocalyptic visions of population change. Andreu Domingo (2008) usefully refers to these texts as forming their own sub-genre: the "demodystopia": a dystopia relating to demographic change and population concerns. He traces shifting concerns with over and under population, migration and eugenics across twentieth century texts. The manipulation of demography in relation to specific ideological investments in futurity is central to the two novels with which the remainder of this paper is concerned: John Wyndham's 1960 Trouble with Lichen and The Unit, by Ninni Holmqvist, first published as Enhet in Swedish in 2006 and in English in 2010. ${ }^{1}$ Conventional literary representations of ageing often shape our imagination of our ageing future by deploying horror motifs of the aged body as grotesque, or focusing on declining fertility and the "burden" of care for the aged. Whereas many other speculative fictions of rejuvenescence and life extension rely on what Rosen refers to as the "Tithonus syndrome", in which everlasting life without everlasting youth leads to "suffering, loneliness, alienation, or boredom" (2002: 70), both Trouble with Lichen and The Unit offer new imaginative engagements with ideas about ageing and the future that counter contemporary representations of ageing.

John Wyndham's Trouble with Lichen concerns the discovery of a rare lichen which has an "antigerone" effect, delaying the ageing process to extend longevity for several hundred years. Ninni Holmqvist's The Unit is set in the Second Reserve Bank Unit for biological material, where those who are old enough to be deemed

${ }^{1}$ We would like to thank Dr Sarah Falcus from the University of Huddersfield for recommending The Unit and for her work on ageing. 


\section{Culture Unbound}

Journal of Current Cultural Research

"not needed", or "dispensable" (childless single women over 50 and childless single men over 60) live in luxury while they take part in experiments and donate biological material and organs until they die. In what follows, we repurpose the five main questions asked by CFS as entry points into these two texts, in order to demonstrate two contrasting ways of thinking through how $\mathrm{SpF}$, in its engagement with ageing, might both critique and endorse concerns about ageing and the future.

\section{John Wyndham, Trouble with Lichen}

We can ask the question "Who can speculate about the future with legitimacy?" in relation to both novels in two different ways: first extra-textually, considering the texts as products existing in a particular field of cultural production and second intra-textually, considering the texts' narrative. Beginning with John Wyndham's novel, we can sum up as follows. Wyndham (1903-1969) was a relatively privileged and establishment figure. Privately educated, he studied farming and law, and briefly worked in advertising and commercial art before beginning writing for the US science fiction magazines in the 1920s and 30s. During WWII he worked as a censor for the British government; after joining the army later in the war, he participated in the 1944 Normandy landings. His first and arguably most well-known novel, The Day of the Triffids, was published in 1951, beginning a successful career as a novelist (Horne 2004). According to the entry in the Encyclopedia of Science Fiction, "In the UK, though not in America, he [Wyndham] was marketed as a middlebrow writer of non-generic work, and was not strongly identified with SF".

Wyndham certainly predates SF's move into what has been termed the "inner space" (Ballard 1962) or "New Wave" SF of the late 1960s and early 1970s (Roberts 2000, Luckhurst 2005) and has most frequently been associated with the "cosy catastrophe" genre (Aldiss 1973) and with conservative, Cold War values. While undoubtedly his work has historically lacked the legitimacy associated with what Bourdieu (1984) terms cultural capital, its popularity (evidenced in the Oxford Dictionary of National Biography entry on Wyndham by markers such as sales figures, film and television adaptations and wealth at death) can be said to serve as a proxy for cultural legitimacy. More recently, scholarly work on Wyndham has focused on some of his better-known texts, for example The Day of the Triffids, as prescient comments on our current environmental concerns (Miller 2012, Link 2015). Trouble with Lichen has never previously been considered as anything other than slight, but we argue here that the novel does suggest, as early as 1960, the emergence of important aspects of our contemporary attitudes to ageing. The re-evaluation of both Wyndham (and for that matter SF as a genre) fits 


\section{Culture Unbound}

Journal of Current Cultural Research

with Bourdieu's thesis about the permeability of the field of cultural production, questioning the categories and values of high and low culture and demonstrating the capacity for particular texts, genres and authors to move flexibly amongst them.

Within the pages of the novel itself, ideas about legitimacy in relation to speculations about the future are of great significance and overlap with CFS second and third questions: "Whose imagined futures are deemed possible and plausible and whose are silenced and dismissed?" The secret of the lichen's antigerone properties is discovered and developed by two different characters: Francis Saxover - the head of a private biosciences research centre - and Diana Brackley, a young graduate who works for him. Although the accidental discovery of the lichen's antigerone properties is made together, both characters continue to develop the drug separately. Saxover begins to treat his adult son and daughter, initially without their knowledge, but otherwise keeps the discovery secret. He expresses concerns about "the chaos that would follow in a world which is already overpopulated, with a birth rate far too high" (1960; 2008: 58). Saxover here expresses views that were certainly beginning to be current at the time of the novel's publication. As Andreu Domingo remarks, the period 1950 to 1975 saw "debate on the evolution of population [...] move beyond the academic field of demography $[\ldots]$ and into the public domain" (2008: 728). He particularly notes the popular influence of Paul R. Erlich's best-selling 1968 The Population Bomb, with its vision of mass famine in what we would now call the global south and its call to writers to engage with this issue in their work (729). The imagery of explosion - perhaps particularly apposite given the creation of the atom bomb and its testing throughout the 1950s - is also used by Saxover, who describes his discovery as follows: " 'It isn"t as spectacular as the nuclear boys' fireworks, but it's more important - in its way it is more disruptive" (58). Given that the lichen that is used in the production of the antigerone is extremely rare, Saxover is also concerned about inequality and exploitation. As he puts it: "Who are going to be the lucky ones that are allowed to live longer. And why?"'(59).

In contrast, Diana perceives the antigerone as a breakthrough of particular significance for women. Her view is that the extra lifespan provides women with opportunities to be more than wives and mothers and that the constraints of reproduction and childcare, with their explicit burdens on women, can thus be evaded, or, more accurately, assume a more proportionate place in a woman's experience. The promise of first-wave feminism can thus be achieved by providing space and time for women to challenge gender ideologies and acquire power. She remarks: 


\title{
Culture Unbound
}

Journal of Current Cultural Research

\begin{abstract}
"My great-aunt fought, and went to prison several times, for women's rights, and what did she achieve? A change of technique from coercion to diddle, and a generation of granddaughters who don't even know they're being diddled - and probably wouldn't care more if they did. Our deadliest susceptibility is conformity, and our deadliest virtue is putting up with things as they are." (45).
\end{abstract}

The word "diddle" here suggests Diana's colloquial way of understanding the importance of internalised ideologies of gender in inducing conformity. She opens a high-class beauty clinic catering to the wives of the powerful and begins secretly to treat her women clients, with the aim of creating an elite group who can fight for women's rights to access the antigerone treatment once she goes public with the discovery. Diana's beauty parlour is a subversive commentary on the emerging conception of age, specifically its appearance on our bodies, as a personal future that needs to be managed or avoided by the consumption of health regimes and beauty procedures (Raisborough et al 2014). Clearly Diana sees this idea of anti-ageing as a cover for the acquisition of real power by women.

Wyndham's representation of Diana's aims can be positioned within the context of post-war ideologies of femininity and contemporary debates about gender politics. While the post-war period up until the birth of the second wave of feminism or women's liberation movement is often seen as retrogressive in terms of gender politics, with women returning to the home to take up roles as wives and mothers, it is argued that this return to domesticity is to some extent a myth buttressed by a conservative ideology of middle-class motherhood (Hanson and Watkins (2017: 6). Robert Yeates (2016: 417) argues that in Wyndham's 1954 Day of the Triffids "hysterical femininity and dominant masculinity seems to emerge from resentment toward the new economic role of women in the years following the Second World War."

However, Diana's actions are viewed differently in Trouble with Lichen, published six years later. For the majority of the narrative, we see events from her perspective and the narrative is sympathetic to her, which means that her actions and judgements in relation to ageing, gender and the future are legitimised. The novel opens with a proleptic description of her funeral, attended by great numbers of women protesters and a "sprinkling of men" (5). This is swiftly followed by a discussion of the life options for such an intelligent, attractive girl as the 18-year-old Diana from the point of view of one of her teachers. At the end of the novel, we learn that Diana faked her own death in order to buy the time to develop the antigerone secretly. The book ends with Diana and Francis planning to marry (Diana under another identity) and making arrangements for the 


\section{Culture Unbound}

continued production of the antigerone. By virtue of its structure, then, the novel also accords legitimacy to her perspective.

In terms of CFS fourth question, in Trouble with Lichen it is women particularly middle-class women - who will benefit from the discovery of the antigerone and the changes in their role and place in the future that the discovery generates. For the most part such changes are envisaged in terms of a greater engagement in the public sphere. In a conversation with her mother at the age of 25, Diana is asked: " "Don"t you want a house of your own, and a family?" In her reply she states: " 'I"ve plenty of time yet." Her mother replies: " Not so long as you think. A woman is always up against time, and it doesn't do to forget it."' (44). It can be argued that the antigerone works in the novel merely to postpone or interrupt conventional heterosexual romantic plots, since Diana's romantic attachment to Francis Saxover is finally rewarded at the end of the book, despite a significant age difference between them. However, the novel encourages the reader to speculate about the interaction between gender, the ageing process and ideas about the future to the extent that we question the amount of time that childcare and domesticity take in women's lives. We are encouraged to ask what the limiting of those roles (in terms of the time they take within an elongated lifespan) might allow women to achieve in other areas. Life extension and a slowing of the ageing process then become devices that enable critical consideration of contemporary social arrangements and gender ideologies rather than merely fantasies of "bio-engineering ageing out" (Mangum, 2002:69).

The imagined futures that are silenced and dismissed in the novel (CFS third question) reveal some of its more disturbing and conventional colonial and classist aspects. The small supply of lichen is grown in Hokiang, a province of Manchuria, north of Vladivostock. Diana has used an agent in Hong Kong (then still under British control) to harvest the lichen. Typical Cold War concerns about the involvement and interference of the Russian and Chinese governments are expressed by both Diana and Francis, with British imperial exploitation of the produce of countries beyond the Iron Curtain taken as normative. The idea of sharing the lichen and its properties with people of other countries or cultures is not even considered; the novel concludes with the lichen apparently growing successfully in Diana's garden. Indeed, we are told that the Chinese suppress and destroy the lichen, an action viewed as understandable given their particular concerns with over-population.

Another voice and future that is dismissed in the novel is that of the working-class woman, who exists only as she is summarised in the reported speech of her husband in a short comic interlude where an exchange between two working-class men in a pub is constructed for the reader. "Bill" offers the view that the antigerone is "unnatcheral" (169) and tells his friend that he refuses to allow 


\section{Culture Unbound}

his wife to partake. In these respects, the novel appears far more conventional and of its time. The beneficiaries of the antigerone (CFS q no 4) will be middle-class British women and some men, rather than working-class people or non-British people of either gender.

\section{Ninni Holmqvist, The Unit}

We now turn to consider Ninni Holmqvist's The Unit to assess the extent to which the author and text have, in CFS terms, legitimacy to speculate about the future. Ninni Holmqvist is a Swedish writer born in 1958 who teaches creative writing and works as a literary translator as well as writing fiction. Her work came to international prominence with the translation of Enhet into English as The Unit in 2010. As Sophie Gilbert (2017) comments, the novel's translation was perhaps intended to "capitalize on the feverish interest in reproductive dystopias sparked by Hulu's Emmy-nominated adaptation of The Handmaid's Tale". The book has been compared in reviews to Atwood's novel and indeed Atwood's comment: "I liked The Unit very much...I know you would be riveted, as I was" takes pride of place on the front cover of the 2018 Oneworld paperback edition. Others note some similarities with Kazuo Ishiguro's Booker Prize-shortlisted 2005 novel about cloned boarding school students Never Let Me Go, which was also adapted as a film (released in 2010 in the USA and 2011 in the UK). There is very little critical commentary on The Unit, but what there is often discusses the novel alongside Ishiguro's. Sara Wasson (2015: 105) argues that the novel should be read as science fiction, since it offers readers "speculative visions of future societies" and that the text makes use of the gothic mode. Benedetta Liorsi (2019: 988) positions the book as one of a number of "SF literary and cinematographic texts dealing with the effects of new medical technologies and practices": a medical dystopia that works to critique neoliberal ideology. Key markers of cultural legitimacy or capital that are apparent here include translation into English, comparison with and endorsement by prize-winning literary novelists, and a small emerging scholarly / critical literature.

In the novel itself, questions of legitimacy in relation to the future are explicitly linked to issues of plausibility and silencing (CFS questions 1-3). Being "needed" (in the terms established within the Scandinavian future democracy in which the novel is set) depends on explicitly articulated and agreed terms that equate what Lee Edelman (2004) terms reproductive futurism with value: those without children and partners have to move into units and donate their biological material after the age of 50 (women) and 60 (men). These terms have been agreed by national referendum. Bendetta Liorsi argues that the novel is a subtle critique of the emerging importance in our neo-liberal medical culture of what 


\section{Culture Unbound}

Journal of Current Cultural Research

she names the ante-tempus patient; a role "constructed by the need to preserve health, to deal with diseases not manifested yet, but already envisaged in their future manifestation, and to make health a manipulable object for biopower and bioeconomy" (Liorsi, 2019: 997). In the notion of the anti-tempus patient, Liorsi usefully alerts us to how bioeconomics complicates the conventional discrepancy between the healthy and the ill and is capable of disturbing temporal distinctions between present health and future illness. It is thus able to delay illness for some people by postponing it until the future; by experimenting on the dispensable in the present (thus making them ill) the needed are kept healthy in the future.

The novel opens with the protagonist and narrator of the novel, Dorrit, arriving to live in the unit. As a dispensable person, her relation to the future exists in ways that she tries to re-conceive as social rather than individual. In conversation with her therapist, she states:

"I suppose I used to believe that my life belonged to me ... something that was entirely at my disposal, something no one else had any claim on, or the right to have an opinion on. But I've changed my mind. I don't own my life at all, it's other people who own it." (103)

When asked by her therapist who does own her life, she answers that it is owned by those in power, or the rulers. When asked who are the rulers, she replies:

"We don't really know. The state or industry or capitalism. Or the mass media. Or all four. Or are industry and capitalism the same thing? Anyway, those who safeguard growth and democracy and welfare, they're the ones who own my life. They own everyone's life. And life is capital. A capital that is to be divided fairly among the people in a way that promotes reproduction and growth, welfare and democracy. I am only a steward, taking care of my vital organs." (103)

Dorrit acknowledges that her words here are to some extent ironic (she tells her therapist that she is "working on" believing that this is a meaningful opinion).

The success of the novel lies in the different ways in which readers are engaged sympathetically with Dorrit's coming to terms with, or "working on" her dispensability. As someone whose future is implausible at an individual level, it is important that her voice is accorded plausibility via the device of first-person narrative. She is implausible but not silenced, in CFS terms. The process of our engagement with Dorrit takes place via a number of strategies and motifs typical of critical dystopias, which allow readers and protagonists to "hope [read imagine 


\section{Culture Unbound}

a different non-dystopian future] by resisting closure [and] maintain the utopian impulse within the work" (Baccolini and Moylan 2003: 7).

Initially, the utopian space within the novel emerges via the possibility of resistance. Dorrit's own artistic practice (she is a writer) and that of her friends in the unit marks out one of the first potential spaces in which she can challenge her status as dispensable. The novel includes descriptions of art exhibitions created and curated by the unit's inmates, and paintings which Dorrit believes to have been created by her sister, as well as descriptions of her own short story. In the story she writes while in the unit, a single woman of 45 gives birth to a fully-developed, but deformed, child, the care of which would constitute a significant burden. Dorrit writes that:

The question was: Is this mother to be regarded as a parent in the practical, concrete meaning of the word? Is she to be regarded as needed? The question was: Is a person needed if she gives birth to a child that will never be able to bond with her and will never be able to make any kind of contribution? (93)

The challenge to assumptions about reproductive futurism - that children are necessarily and automatically "the future" - is fairly explicit here. However, as in Ishiguro's Never Let Me Go, within The Unit, art never provides more than a licenced outlet, which in fact serves to customise inmates to their own subjection. With her new writing project, Dorrit repeatedly writes and then immediately deletes her words; she is unable to finish her story.

Readers' next hopes for resistance are brought into play via the plot developments of pregnancy and escape. Dorrit becomes pregnant by her lover within the unit. She assumes that this will entail a recategorization of her status: that she will now become needed and that her future is now plausible (in CFS terms), but it is made clear to her that while her baby is needed, she is not. She is expected either to donate the embryo, or carry the baby to term and give it up for adoption by a younger, childless couple. Her individual future is thus dismissed. The baby's father has already made his last donation, without telling Dorrit that this was about to happen. Devastated by this, Dorrit asks for an application form in order to request to make her own final donation as soon as possible. The novel includes the questions on the form, with attached tick boxes, in the text, including requests to move to another section and another unit as well as to make a final donation. Dorrit ticks this last box, but ignores another option: to make a request "for postponement of a final donation" (195). We can only speculate about why her lover, Johannes, did not apply to postpone his final donation, and more than that, about the very existence of such a question, which implies that there are 


\section{Culture Unbound}

some grounds on which it is possible for a dispensable person to avoid the last stage of donation - or postpone death. Whether or not any such requests are made and whether any are granted, we do not find out.

Dorrit's resignation, her acceptance of her dispensability, and the debate this generates about her agency and her future plausibility, becomes more acute when she is offered escape options. Her application to make her final donation is shredded by a unit employee, who also gives Dorrit the key codes to release the unit's doors to the external world. Dorrit remarks that "The idea of trying to get out, away, escape from here had never crossed my mind" (201). Although she does escape from the unit towards the end of the novel, the novel actually concludes with Dorrit back in the unit, giving birth to and writing a letter to her daughter, and finishing her manuscript: the novel we are reading. She explains in the letter that she did not choose "freedom along with her [daughter] instead of giving her up to someone who can give her security and the chance of a dignified life" (268). The reasons for this are complex: clearly, they include grief and trauma at Johannes's death, and also an obvious internalisation of the value system (around who does and does not have a plausible future) by which she is surrounded.

However, Dorrit's acceptance of her dispensability also contains within it an embryonic challenge to the values of her society, which is apparent in her strong sense of duty to her friend Elsa. Each has agreed to tell the other when her final donation is due. Dorrit states that one of the reasons for her return to the unit is that she "wanted to be there for Elsa [...] But now Elsa is gone too, and no one needs me here anymore, not even myself" (267). Here we again sense a questioning of the distinction between the needed and the dispensable, emerging in the value of friendship. Friendships are in actuality only one of a number of relationships that are posited as challenges to a state model that only positions need in terms of reproductive futurism. Other relationships that exist at a tangent to this model, are othered by it, but are voiced within the text, are relationships between humans and animals (Dorrit is powerfully affected throughout the novel by memories of her dog) and also sibling relationships (it takes Dorrit some time to find out what happened to her older sister and recognise that she also probably ended her life by donation). While dispensable adults' ethical responsibilities for aged parents, friends, siblings, pets and lovers are dismissed (in CFS terms) by the state, they are valued and voiced by the narrative, and acquire prominence as the novel progresses. As Liorsi (2019: 991) comments, in terms that echo the CFS focus on "who benefits" from particular imagined futures: "The focus of the narrative is cast almost exclusively on those who do not seem to benefit from the democratic state of things, but who are instead the objectified products and usable tools of such a democracy." What is more disturbing is that Dorrit's ethical responsibility to her friend Elsa eventually works in tandem with the state's explicit ideology to 


\section{Culture Unbound}

engineer her choice to return to the unit, have her baby adopted and make her final donation.

\section{Conclusion: Whose Future?}

This paper set out to argue that a critical account of ageing was required for CFS. We argue that ageing makes for a timely and fertile study as part of CFS not least because ageing presently manifests across media and policy as a pressing future crisis (Carney 2018). We can point to advertising, lifestyle media, and global biomedical and pharma-cosmetic industries which variously present age, specifically its future appearance on our bodies, as a personal future that needs to be managed or avoided by the consumption of health regimes, beauty procedures, surgery and bioengineering: these promise access to better personal futures (Petersen 2018, Ellison 2020). Yet, rather than suggest age and ageing is an interesting additional site of study for CFS, we want to argue for the necessity of an age-aware CFS.

This helps progress nascent areas of development in CFS - bodies and stories - but more than that, it is also crucial for a critical grasp on how imaginations of the future play a part in imaginations now that have brutal material realities. This paper was devised before the Covid-19 pandemic. We could not have foreseen AGE and COVID - how imaginations failed - how care homes and vulnerable people were failed. We argue that an age-aware CFS can allow us not only to imagine new futures but also to reflect critically on the shape and consequences of contemporary modes of relations of power.

We also argue that Speculative Fiction is a space that can only clarify our understanding that all bodies are "first and foremost social" and that the task is to have a "clearer understanding not just of ageing but of embodiment at all stages of the lifecourse" (Pickard 2014: 1279). Our varying and changing experiences of ageing need to be rescued from a neoliberal system that forces a disavowal of dependency and vulnerability; instead, we need to recognise care and dependence as elements intrinsic to being human.

Speculative fiction also asks the question: who is the future for? It calls for closer attention to the related issues of who is represented and voiced, questions that are central in the two SpF texts examined here. As Wälivaara has it:

The stories we are told about ourselves and others impact the way we understand our society and how we view and value people [...] To constantly meet the same type of stories and stereotypes, not only in fiction but also in other parts of society, can influence one's world view. Certain groups, in particular those already marginalized in society, are 


\section{Culture Unbound}

Journal of Current Cultural Research

constantly framed within the same type of story, which contributes to normative understandings of these groups. They are normative in the way they help sustain normative notions about groups, often by clear divisions between us/them and normal/deviant. (2018: 232)

The voicing and legitimisation of those who are marginalised that $\mathrm{SpF}$ undertakes, plus the variety of narrative possibilities it provides are vital because they destabilise normative projections and imaginations of the future and ageing, allowing us not only to imagine new futures but also to reflect on the shape and consequences of contemporary modes of relations of power. This double emphasis is neatly captured by Attebery (2002: 191) for whom, "any group that cannot negotiate a place for itself in the imagined future is already obsolete". Many readers of The Unit might find it a frustrating experience precisely because it does not allow Dorrit to negotiate such a place for herself; the novel avoids the expected and hoped-for outcomes of resistance and escape. In fact, it is an intelligent meta-commentary on that particular narrative. In comparison, John Wyndham does allow his heroine, Diana, to create a future for herself. Writing about Trouble with Lichen in the Guardian, Nicholas Lezard (2008: n.p.) remarks that "for a while I was wondering when John Wyndham [...] was going to show us all how silly these women are really being. But it becomes fairly clear, fairly quickly, that this isn't going to happen. Diana Brackley is simply too sympathetically drawn, although an unreconstructed male in 1960 would have been pretty terrified of her." In our reading, then, The Unit operates via the more "literary" device of metafictional commentary on the conventions of recent reproductive dystopias, but is the more implicitly negative in its vision of inescapable elderly dispensability in the future. Despite its earlier date of publication, The Trouble with Lichen is an interesting and positive speculation about how it might be possible to alter the interaction between gendered labour, the ageing process and ideas about the future. However, other readers might interpret these texts quite differently from how we have here and it is therefore impossible to isolate definitively the precise impacts of a text on a readership, or, for that matter, a specific reader. Despite this we can point to the ambivalence of SpF's imaginative visions of the future as the specific, important space for possible contestation of dominant conceptions of the future and ageing. Margaret Atwood's term ustopia is again important here because it emphasises the ambiguities of texts like Trouble with Lichen and The Unit that engage both dystopian and utopian elements. As Susan Watkins (2020: 9) explains, the term also "reminds us that we, as readers, are implicated in these texts and their visions of the future: it is we, or "us", who are being addressed and asked to respond."

Ageing is deeply entwined with futurity: if we are lucky an older life awaits us. Yet, this paper is premised on the argument that our age is far from a neutral 


\section{Culture Unbound}

Journal of Current Cultural Research

descriptor, because it takes its meaning and significance from wider socio-cultural and economic contexts, including speculative fiction, a genre which, we argue, is particularly well-placed to challenge that apparent neutrality.

\section{References}

Aldiss, Brian (2015): "John Wyndham," Oxford Dictionary of National Biography, https://www.oxforddnb.com (accessed 01/05/20).

Aldiss, Brian (1973): Billion Year Spree: The History of Science Fiction, London: Weidenfeld and Nicolson.

Anon (2020): "John Wyndham," The Encyclopedia of Science Fiction, http://www. sf-encyclopedia.com/entry/wyndham_john (accessed 01/05/20).

Attebery, Brian (2002): Decoding Gender in Science Fiction, Abingdon: Routledge. Attridge, Derek (2004): The Singularity of Literature, Abingdon: Routledge.

Atwood, Margaret (2011): In Other Worlds: Science Fiction and the Human Imagination, London: Virago.

Baccolini, Raffaella \& Tom Moylan (2003): Dark Horizons: Science Fiction and the Dystopian Imagination, New York: Routledge.

Ballard J. G. (1962): “Which Way to Inner Space?” New Worlds, 118: 2-3, 116-18.

Boudiny Kim (2013) "Active Ageing: From Empty Rhetoric to Efficient Policy Tool," Ageing and Society, 6:1077-1098.

Bourdieu, Pierre (1984): Distinction: A Social Critique of the Judgement of Taste, trans. Richard Nice, London: Routledge and Kegan Paul.

Calasanti, Toni. M. (2020): "Brown Slime, the Silver Tsunami, and Apocalyptic Demography: The Importance of Ageism and Age Relations," Social Currents, 7: 3, 195-211.

Carney, Gemma. M (2018): “Towards a Gendered Politics of Ageing," Journal of Women and Ageing, 30: 3, 242-258.

Coleman, Rebecca (2017): "A Sensory Sociology of the Future: Affect, Hope and Inventive Methodologies," The Sociological Review, 65: 3, 525-543.

David Coleman, Stuart Basten \& Francesco C. Billari (2015): "Population-The Long View," Population Studies, 69, sup1: S1-S9.

Coupland, Justine (2009): "Time, the Body and the Reversibility of Ageing: Commodifying the Decade," Ageing \& Society, 29: 953-976.

Crawford, Robert (1980): "Healthism and the Medicalization of Everyday Life," International Journal of Health Services, 10: 3, 365-388. 


\section{Culture Unbound}

Journal of Current Cultural Research

Delgado, Ana, Kjetil Rommetveit, Miquel Barcelo, \& Louis Lemkow (2012): "Imagining High-Tech Bodies: Science Fiction and the Ethics of Enhancement," Science Communication, 34: 2, 200-240.

Domingo, Andreu (2008): "Demodystopias: Prospects of Demographic Hell," Population and Development Review, 34: 4, 725-45.

Edelman, Lee (2004): No Future: Queer Theory and the Death Drive, Durham, N.C.: Duke University Press.

Edström, Maria (2018): "Visibility Patterns of Gendered Ageism in the Media Buzz: A Study of the Representation of Gender and Age over Three Decades," Feminist Media Studies, 18: 1, 77-93.

Ellison, Kirsten (2020): "Upgraded to Obsolescence: Age Intervention in the Era of Biohacking," Engaging Science, Technology and Society, 6: 39-4 4.

Evans, Robert G., Kimberlyn. M. McGrail, Steven. G. Morgan, Morris. L Barer \& Clyde Hertzman (2010) "Apocalypse No: Population Aging and the Future of Health Care Systems," Canadian Journal on Aging / La Revue Canadienne Du Vieillissement, 20 (S1), 160-191.

Erlich, Paul (1968): The Population Bomb, Cutchogue, N. Y.: Buccaneer Books.

European Commission (2018): "The 2018 Ageing Report: Economic \& Budgetary Projections for the 28 EU Member States (2016-2070)," Institutional Paper 079, May, https://ec.europa.eu/info/sites/info/files/economy-finance/ip079 en.pdf (accessed 15/02/21)

Gee, Ellen (2002): "Misconceptions and Misapprehensions about Population Ageing," International Journal of Epidemiology, 31: 750-753

Genette, Gerard (1980) Narrative Discourse: An Essay in Method, trans. Jane E. Lewin, Ithaca: Cornell University Press.

Gilbert, Sophie (2017) "The Swedish Novel That Imagines a Dystopia for the Childless," The Atlantic 25 July https://www.theatlantic.com/entertainment/ archive/2017/07/the-unit-review-ninni-holmqvist/534651/(accessed 22/07/20)

Godhe, Michael \& Luke Goode (2018): "Critical Future Studies: A Thematic Introduction," Culture Unbound: Journal of Current Cultural Research, 10: 2, 151-162.

Goode, Luke \& Michael Godhe (2017): "Beyond Capitalist Realism - Why We

Need Critical Future Studies," Culture Unbound: Journal of Current Cultural Research, 9:1, 108-129.

Gullette, Margaret Morganroth (2011): Agewise: Fighting the New Agism in America, Chicago: The University of Chicago Press.

Hanson, Clare \& Susan Watkins (2017): The History of British Women's Writing Vol IX: 1945-1975, London: Palgrave Macmillan.

Harper, Sarah (2018): Demography: A Very Short Introduction, Oxford: Oxford University Press. 


\section{Culture Unbound}

Journal of Current Cultural Research

Holmqvist, Ninni (2006; 2010): The Unit, trans. Marlaine Delargy, London: Oneworld.

Horne, Alastair (2004): “John Wyndham," Proquest Biographies, https://searchproquest-com (accessed 01/05/20).

Ishiguro, Kazuo (2005): Never Let Me Go, London: Faber and Faber.

Iversen, Sara Mosberg \& Monika Wilińska, (2020): “Ageing, Old Age and Media: Critical Appraisal of Knowledge Practices in Academic Research", International Journal of Ageing and Later Life, 14: 1, 1-29.

Katz, Stephen (2005): Cultural Aging: Life Course, Lifestyle and Senior Worlds. Peterborough: Broadview Press.

Lafontaine, Céline (2009): "Regenerative Medicine's Immortal Body: From the Fight against Ageing to the Extension of Longevity," Body and Society, 15: 4, 53- 71.

Lezard, Nicholas (2008): “Apocalypse Then," Guardian, 23 August 2009: https:// www.theguardian.com/books/2008/aug/23/fiction (accessed 01/05/20)

Liberini, Federica, Andrew J. Oswald, Eugenio Proto \& Michela Redoano (2017): "Was Brexit Caused by the Unhappy and the Old?", IZA Discussion Papers, No. 11059, Bonn: Institute of Labor Economics (IZA).

Link, Miles (2015): ““A Very Primitive Matter': John Wyndham on Catastrophe and Survival," The Irish Journal of Gothic and Horror Studies, 14, 63-80.

Liorsi, Benedetta (2019): “The Ante-Tempus Novel: Prevention and Patienthood in Recent Speculative Fiction," Textual Practice, 33: 6, 983-1003.

Luckhurst, Roger (2005): Science Fiction, London: Polity Press.

Lundgren. Anna Sofia \& Karin Ljuslinder (2011): “'The baby-boom is over and the ageing shock awaits': Populist Media Imagery in News-Press Representations of Population Ageing," International Journal of Ageing and Later Life, 6: 2, 39-71.

Macia, Enguerran, Dominique Chevé \& Joann M. Montepare (2019): “Demographic Ageing and Biopower," Journal of Ageing Studies 51, 100820.

Mangum. Teresa (2002): "Longing for Life Extension: Science-Fiction and Later Life," Journal of Ageing and Identity, 7: 69-82.

Marshall, Barbara L. (2018): "Happily Ever After? 'Successful Ageing' and the Heterosexual Imaginary”, European Journal of Cultural Studies, 21: 3, 363-381.

Marmot, Michael (2020): "Health Equity in England: The Marmot Review 10 Years On," The British Medical Journal, 368: m693.

Miller, T. S. (2012): "Lives of the Monster Plants: The Revenge of the Vegetable in the Age of Animal Studies," Journal of the Fantastic in the Arts, 23: 3, 460-479.

"Ninni Holmqvist", http://www.nordinagency.se/clients/fiction/ninni-holmqvist/ (accessed 01/05/20)

Nelson, Todd, D (2005): “Ageism: Prejudice Against our Feared Future Self," Journal of Social Issues, 61:2, 207-221. 


\section{Culture Unbound}

Journal of Current Cultural Research

Parcei, Natasha (2019): "The Representation of Older Women in Twenty-first Century Horror: An Analysis of Characters Played by Jessica Lange in American Horror Story," Steven Gerrard, Samantha Holland \& Robert Shail (eds.) Gender and Contemporary Horror in Television, Bingley: Emerald Publishing, 47-57.

Petersen, Alan (2018): "Capitalising on Ageing Anxieties: Promissory Discourse and the Creation of an 'Anti-Ageing Treatment' Market," Journal of Sociology, 54: 2, 191-202.

Pfaller, Larissa \& Mark Schwed (2019): "Excluded from the Good Life? An Ethical Approach to Conceptions of Active Ageing," Social Inclusion, 7:3, 44-53.

Pickard, Susan (2014): 'Biology as Destiny? Rethinking Embodiment in 'Deep' Old Age," Ageing and Society, 34, 1279-1291.

Pickard, Susan (2019): "Age War as the New Class War? Contemporary Representations of Intergenerational Inequity, Journal of Social Policy, 48:2, 369-386

Raisborough, Jayne, Marian Barnes, Flis Henwood \& Lizzie Ward (2014): "Stretching Middle Age: the Lessons and Labours of Active Aging in the Makeover Show," Media, Culture \& Society, 36:8, 1069-1083.

Roberts, Adam (2000): Science Fiction, London: Routledge.

Samuelson, David M. (2009): "Hard SF", The Routledge Companion to Science Fiction, Abingdon: Routledge. https://search-proquest-com (accessed 01/05/20)

Schulz, Markus S. (2015): "Future Moves: Forward-Oriented Studies of Culture, Society, and Technology," Current Sociology, 63:2, 129-139.

Segal, Lynne (2013): Out of Time. London: Verso.

Slusser, George, Gary Westfahl, \& Eric S, Rabkin (1996): Immortal Engines: Life Extension in Science Fiction and Fantasy, Athens: G.A.: The University of Georgia Press.

Smallwood, Steve (2019): "Why Demography Matters; Demography: A Very Short Introduction," Population Studies, 73: 2, 291-294.

Teitelbaum. Michael. S (2015): "Political Demography: Powerful Trends Under-Attended by Demographic Science," Population Studies, 69: sup1, S87-S93.

Traies, Jane (2016): The Lives of Older Lesbians: Sexuality, Identity and the Life Course. London: Palgrave.

Twigg, Julia \& Wendy Martin (2015): "The Challenge of Cultural Gerontology," The Gerontologist, 55: 3, 353-359.

United Nations, Department of Economic and Social Affairs, Population Division (2019): "World Population Prospects 2019: Highlights (ST/ESA/ SERA/423)," New York, https://population.un.org/wpp/Publications/Files/ WPP2019 10KeyFindings.pdf (accessed 15/2/21). 


\section{Culture Unbound}

Wälivaara, Josefine (2018): "Marginalized Bodies of Imagined Futurescapes: Ableism and Heteronormativity in Science Fiction," Culture Unbound, 10: 2, 226-245.

Wasson, Sara (2015): "Scalpel and Metaphor: The Ceremony of Organ Harvest in Gothic Science Fiction," Gothic Studies, 17: 1, 104-123.

Watkins Susan (2020): Contemporary Women's Post-Apocalyptic Fiction, London: Palgrave Macmillan.

Westwood, Sue (ed.) (2019): Ageing, Diversity and Equality: Social Justice Perspectives. Abingdon and New York: Routledge.

Woodward, Kathleen (2019): "Afterword: Literary Antidotes to the Toxin that is Ageism," Studies in American Fiction, 46: 2, 373-381.

World Health Organisation (2018): "Ageing and Health: Fact Sheet," $5^{\text {th }}$ February, https://www.who.int/news-room/fact-sheets/detail/ageing-and-health (accessed 13/9/19).

Wyndham, John (1960; 2008): Trouble with Lichen, London: Penguin.

-. (1951; 2008): The Day of the Triffids. London: Penguin.

Yeates, Robert (2016): "Gender and Ethnicity in Post-Apocalyptic Suburbia," Journal of the Fantastic in the Arts, 27: 3, 411-434.

Ylänne Virpi (ed.) (2012): Representing Ageing: Images and Identities. Basingstoke: Palgrave Macmillan.

\section{Author Presentations:}

Jayne Raisborough is Professor of Media in the School of Cultural Studies and Humanities at Leeds Beckett University, UK. j.raisborough@leedsbeckett.ac.uk https://www.leedsbeckett.ac.uk/staff/professor-jayne-raisborough/

Susan Watkins is Professor of Women's Writing in the School of Cultural Studies and Humanities at Leeds Beckett University, UK. s.watkins@leedsbeckett.ac.uk https://www.leedsbeckett.ac.uk/staff/professor-susan-watkins/

The authors would like to thank the reviewers for their support and suggestions for this paper. 